\title{
CONTRIBUTIONS FROM THE CAPABILITIES APPROACH TO THE HUMAN RIGHTS PRACTICE
}

\section{CONTRIBUIÇÕES DA TEORIA DE CAPACIDADES PARA A PRÁTICA DOS DIREITOS HUMANOS}

\author{
Gabriela Cristina Braga Navarro ${ }^{1}$
}

\begin{abstract}
The article analyses the contributions offered from the capabilities approach to the human rights theory. The capabilities approach is a theory developed by Martha Nussbaum, US-American philosopher, that analyses the basic capabilities (alternative combinations of functionings that a person have the possibility to achieve) necessary for achieving a life with dignity, with special focus on gender vulnerability. The article demonstrates that Nussbaum's theory contributes greatly for the practice of human rights, by offering a list of specific capabilities that should be guaranteed to every human being by the State, with particular concern for vulnerable groups such as women, children and elderly. Even though the theory presents indisputable contributions, criticism is also presented, based upon mostly its essentialist point of view. In order to achieve the proposed objective, the methodology applied was bibliographical review.
\end{abstract}

Keywords: Capabilities approach; human rights; valuable functionings; Martha Nussbaum; social justice.

\section{RESUMO}

O artigo analisa as contribuições oferecidas a partir da abordagem das capacidades à teoria dos direitos humanos. A abordagem das capacidades é uma teoria desenvolvida por Martha Nussbaum, filósofa norte-americana, que analisa as capacidades básicas (combinações alternativas de funcionalidades que uma pessoa tem a possibilidade de alcançar) necessárias para alcançar uma vida com dignidade, com especial enfoque na vulnerabilidade de gênero. $\mathrm{O}$ artigo demonstra que a teoria de Nussbaum contribui muito para a prática dos direitos humanos, ao oferecer um elenco de competências específicas que devem ser garantidas a todo ser humano pelo Estado, com particular atenção para os grupos vulneráveis como mulheres, crianças e idosos. Ainda que a teoria apresente contribuições indiscutíveis, a crítica também é apresentada, fundamentada principalmente em seu ponto de vista essencialista. Para atingir o objetivo proposto, a metodologia aplicada foi a revisão bibliográfica.

Palavras-chave: Abordagem das capacidades; direitos humanos; funcionalidades valiosas; Martha Nussbaum; Justiça social.

\footnotetext{
${ }^{1}$ Doutorado em andamento em Direito na universidade Goethe Universität Frankfurt am Main. Mestrado em Direito (Conceito CAPES 6) na Universidade Federal de Santa Catarina. Graduação em Direito na Universidade Estadual Paulista Júlio de Mesquita Filho, UNESP. Johann Wolfgang Goethe Univertät - Alemanha. Lattes: http://lattes.cnpq.br/2845232560128491 E-mail: gabrielabnavarro@gmail.com
} 


\section{INTRODUCTION}

Over the past century, human rights have become worldly accepted, built around the idea of universal recognition of human dignity. However, several questions emerge in the daily practice, generating controversies and doubts. In the centrality of the debate, the question relative to what are the elements that compose the human rights rises, as well as if it is possible to establish a hierarchy among them. Even when the composition of human rights is clear, it is also controversy how their effectiveness can be measured and how to guarantee equitable rights to vulnerable groups. Theories of social justice have tried to answer the questionings by different start points, such as preferences (ARROW, 1951), freedom (HAYEK, 2013) and recognition (FRASER; HONNETH, 2003). Among them, the capabilities approach focus on the basic capabilities a person has access to. The purpose of the present paper is to offer an introductory analysis to the capabilities approach elaborated by Martha Nussbaum and present its contributions to the human rights practice. The problem the article proposes to answer is, to what extent the capabilities approach contributes to current debates in the human rights practice.

The capabilities approach is a theory of development elaborated since the eighties with the purpose of establishing parameters to measure freedom of the citizens to choose and to perform certain valuable functionings. The central scholars that proposed and developed the theory are the Indian economist and Nobel Prize winner Amartya Sen and the North-American philosopher Martha C. Nussbaum. Both authors present very similar aspects of the theory, with some light divergences. The focus of the present paper is of Martha Nussbaum's approach, even though divergences with Sen's work will be presented for comparative purpose.

Martha Nussbaum was born in 1947 in New York City. Her master and doctorate were received on Harvard University, where she also taught for a while. Currently, she is the Ernst Freund Distinguished Service Professor of Law and Ethics, teaching at the University of Chicago. Her studies are focused on Ancient Greek and Roman philosophy, feminist philosophy, political philosophy, and philosophy and the arts (SKINNER, 2017). While she was in Harvard, she faced reiterated sexism, suffering with sexual harassment and lack of childcare support (she had a baby while studying there). This aspect influenced her future works, as not only she will recognize herself as a feminist, but also her work will reflect the continuous concern about women equality (NUSSBAUM, 2003). All her career is, in his words, "about the 
search for the conditions of human flourishing", especially for women (SKINNER, 2017: online).

The capabilities approach aims to guide policy choice in the way to extinguish "unjustifiable human inequalities", and it has been elaborated considering the needs of developing nations and poorer countries struggling to offer better life quality to their citizens. However, it could be also applied to developed nations, as they also have some problems regarding inequality and well-being (NUSSBAUM, 2011:15-16). Considering the importance of the thematic, as well as the evident practical impact that the theory offers to all-day life, Nussbaum highlights that the capabilities approach is not only a theoretical framework, but actually a way of life (NUSSBAUM, 1995:16).

The paper is divided into three parts. First, central aspects and concepts of the theory are presented. Special attention is given to the gender perspective (a central issue for Nussbaum). The second part is aimed at the comprehension of the contributions from the theory to the human rights practice, including presentation of the capabilities approach as a counter theory to other social justice theories. Finally, in a third part, criticisms to Nussbaum's theory are presented and, when available, the answer proposed by the author is also analyzed. The article concludes that Nussbaum's theory can offer an interesting approach to human rights, specifying the content of adopted legislation and providing a framework for the recognition of the interdependence among different rights.

\section{CENTRAL ASPECTS OF THE CAPABILITY APPROACH}

In order to understand the systematic of the approach, first of all one must understand the basic concepts of the theory. One central concept is "functionings". Sen defines functionings as the various things that a person manages to do or be in leading a life (for example, being in good health, being social integrated, not starving, etc.) (SEN, 1993:31). Nussbaum adopt the same general concept, but there are some small practical differences between the authors. The act of choosing an action is for Sen a distinguishable functioning, and for Nussbaum it is only a chosen dimension of a human functioning. In addition, for Sen, happiness and pleasure are distinguishable functionings, and for Nussbaum pleasure is only supervening of a functioning (CROCKER, 1995: 154 - 155). 
The alternative combinations of functionings that a person has the possibility to achieve, and from which he or she can choose one collection, is called "capability". Functionings are the active realization of the capability (NUSSBAUM, 2011:25). In order to distinguish the concepts of functioning and capability, Sen provides a very interesting example. Consider that two people are starving, but one is for the absence of food, and the other is in a hunger strike. They have the same functioning (to starve), but only one of them has the capability not to starve. Capabilities bring to human life an intrinsic improvement, namely, positive freedom of available and worthwhile options (SEN, 1988).

There are also some distinctions of the capability concept between Nussbaum and Sen. For Sen, capability connotes possibility, or opportunity. Sen would consider capability as option for action, which may refer but are not identical with traits of a person (CROCKER, 1995:154). In other words, capabilities, for Sen, are "substantial freedoms", a block of interrelated opportunities that one can choose and act (NUSSBAUM, 2011:20). For Nussbaum, capability is understood as general powers of a person (internal capability).

The differentiation of concepts can be better understood when we analyze a critic offered by Crocker to the position assumed by Sen, regarding the assumption that there are possible functionings that are bad, like the abilities to torture, to rape and to degrade. If we accept that capabilities are powers, as proposed by Nussbaum, which would allow the assumption that "some powers are bad: not just to exercise, but also to have, acquire or nurture" (CROCKER, 1995: 168-169). Such conclusion would not be possible if we considered capabilities as possibilities.

Nussbaum establishes levels of capabilities. The states of a person are internal capabilities and the outside factors are external capabilities. It is an important distinction, as these two capabilities represent two distinct tasks of a society, making it possible to diagnose social achievements and shortcomings. However, the distinction "is not sharp as they may dialogue in specific conditions." (NUSSBAUM, 2011:20). Combined capabilities "are not just abilities residing inside a person, but also the freedoms or opportunities created by a combination of personal abilities and the political, social, and economic environment" (NUSSBAUM, 2011:20).

Another level established are the basic capabilities, innate equipment that can be nourished before a person is even born (through an adequate maternal nutrition) and continues during the early formation of a child. Such capabilities make training and development further 
possible (NUSSBAUM, 2011:24). When the basic capabilities of human being are not nourished, it is not possible for any person to develop to high-levels capabilities (NUSSBAUM, 1995:85).

Based upon the mentioned concepts, the capability approach can be conceptualized as the "approach to comparative quality-of-life assessment and to theorizing about basic social justice". Nussbaum highlights the importance of the use of "capabilities approach", in plural, to demonstrate that "the elements for a good life are plural and qualitatively distinct, which is one key assumption for the theory" (NUSSBAUM, 2011:18). The central questions proposed by the theory are: what are the people of the country in question actually able to do and to be? How all the groups in the population are doing, comparing the functioning of one group with another? (NUSSBAUM, 1995:4).

For the approach, quality of life should be assessed in terms of capability to achieve valuable functionings (SEN, 1993:30) and development should be considered the promotion and expansion of valuable capabilities (CROCKER, 1995: 157). This leads to the conclusion that governments are obliged "to improve quality of life for all people, as defined by their capabilities" (NUSSBAUM, 2011:19).

The evaluation of capabilities and functionings are central for the capabilities approach, as the central focus must be on the "valuable functionings". As Sen states, "the capability approach is concerned primarily with the identification of value-objects, and sees the evaluative space in terms of functionings and capabilities to function" (SEN, 1993:32). In a similar position, Nussbaum asserts that the approach should ask "among the many things that human beings might develop the capacity to do, which ones are the really valuable ones, which are the ones that a minimally just society will endeavor to nurture and support" (NUSSBAUM, 2011:28).

\section{THE LIST OF CAPABILITIES}

Concerning the evaluation task, there is a central distinction between Sen and Nussbaum. Sen emphasizes the importance of evaluating capabilities and functionings, but has only presented scattered suggestions of valuable capacities (CROCKER, 1995: 170-171). Sen, actually, is very critical to the presentation of a fixed universal list of capabilities, as he assumes 
that each different context and each singular purpose demand a specific list of capabilities (SEN, 2005: 157). Such criticism will be better analyzed infra.

Nussbaum has offered a general and systematic account of good human functionings. She presents a stand on substance, ranking capabilities that are more important than others and the ones that are good or bad (NUSSBAUM, 2011:28). For Nussbaum, considerations regarding capabilities are not ahistorical, biological or metaphysical. It is an evaluative inquiry, intended to be cross temporal and cross borders, presenting "a specially deep and continuous sort of experiential and historical truth", resulting on a normative conception (NUSSBAUM, 1995:74).

The proposal is intended to be universalist and essentialist, assuming that the human beings are all the same (focus on similarities). Also, the evaluation considers a binary approach, for example, opposing life and death, health and illness. It is a metaphysical vision that assumes there is a natural and specific way of all the things to be. Such assumptions will be a focus for diverse critics, meanly from relativist (NUSSBAUM, 1995:64). They will be analyzed in the next topic.

For the evaluative task, two concepts are represented as essential: dignity and a life worth of it. Dignity is an open concept and its use could lead to mistake and inconsistency. To avoid that, the author connects the concept with others from the theory: "the basic idea is that some living conditions deliver to people a life that is worthy of the human dignity that they possess, and others do not" (NUSSBAUM, 2011:30). Dignity should be understood as something inherent that ought to be developed, being equal in all those who are agents, deserving equal respect from the law.

In earlier works, Nussbaum presented the evaluation of capabilities based upon two thresholds, capability to function without there is no human life; and capability for a good human life. In general, when the first group is assured, the second is supplied by the citizen own powers. The quality-of-life assessment asks whether "all citizens are capable, not just of the bare minimum, but of good life in these areas" (NUSSBAUM, 1995:81). The difference of the two thresholds is not expressly present on the latest work, even though the distinction is elaborated in terms of basic capabilities (minimum to survive) and combined capabilities (live a good life) (NUSSBAUM,2011).

The capabilities presented by Nussbaum on her list are the ones that are so central that "their removal makes a life not worthy of human dignity" (NUSSBAUM, 2011:31). The list presented by Nussbaum is the following one (NUSSBAUM, 2011:33-34). 
1. Life in a normal length

2. Bodily health: reproductive health, nourishment and shelter

3. Bodily integrity: liberty of movement, protection against violence (including sexual assault and domestic violence) and sexual satisfaction

4. Senses, imagination and thought: literacy, freedom of expression, pleasant experiences and avoidance of pain

5. Emotions, such as love, grieve and attachments to things

6. Practical reason, entailing liberty of conscience and religion observance

7. Affiliation: social interaction (including freedom of assembly and political speech) and nondiscrimination

8. Other species: "being able to live with concern for and in relation to animals, plants and the world of nature"

9. Play and recreational activities

10. Control over one's environment, including political participation and right to property, both movable and land.

In earlier works (NUSSBAUM, 1995 and SEN, 1993), the list had a different composition. The freedom of movement and sexual satisfaction were part of capability 2 ; the capability to feel pleasure and avoid pain was a separated one (number 3); the right to property was included in the new list, before there was only the capability of "being able to have attachments to things" (number 5); the capability 10 was presented as "principle of separateness", and now it is presented as "control over one's environment", even though the meaning remains the same.

There are some important considerations regarding full comprehension of the list of capabilities. First, the list leaves some matters to be settled by the political process; in other words, it is general in order to leave room for democratic deliberation (NUSSBAUM, 2011:32). The capabilities are abstract and should be specified in each nation through its constitution or basic principles, or yet considering its tradition and history. Also, the threshold should be established within national reach. The capabilities approach "does not dictate final assignment of weights and a sharp-edged decision". This level should be aspirational but not utopian, forcing the nation to do better (NUSSBAUM, 2011:41).

Second, the capabilities are individual, and only derivatively to groups. Each person should be considered individually for purpose of policy making. Group-based policies, such as affirmative actions, should be justified only when they represent instruments for creation of individual capabilities (NUSSBAUM, 2011:35).

Third, the capabilities are distinctive and they need to be guaranteed separately, as "respect for human dignity requires that citizens be placed above an ample (specified) threshold of capability, in all ten of those areas". It is a list of separate components, all of which have 
central importance, even though some capabilities are related to one another (NUSSBAUM, 2011:36).

Fourth, it is possible that in some particular factual conditions the accomplishment of two or more capabilities is in conflict. The capabilities have intrinsic value and should be not analyzed through a cost-benefit approach. There should be no preference among the options, both should be accomplished: "we ask what the best intervention point is to create a future in which this sort of choice does not confront people" (NUSSBAUM, 2011:39).

Nussbaum find it possible to identify the source of the conflict and eliminate it, or, at least mitigate it. In other words, Nussbaum finds it possible to change a social order that causes conflict between capabilities. Another mechanism presented by Nussbaum to solve conflicts within norms is eschewing a priori priority rules and analyzing each particularity of the unique situations. As Crocker states, "we should consider changing the world, so as to eliminate conflict, and penetrating more deeply into the world, so as to discern the most pressing good in that context" (1995: 178-180).

Reaffirming the importance of full implementation of the theory, Nussbaum states: "my claim is that a life that lacks any one of these capabilities, no matter what else it has, will fall short of being a good human life. So it would be reasonable to take these things as a focus for concern, in assessing the quality of life in a country and asking about the role of public policy in meeting human needs" (NUSSBAUM, 1995:85).

Lastly, based upon the concept of capability security, Nussbaum highlights that the citizens must count with some capability in the future, imposing that neither the market nor the power politics can diminish them, except by "a laborious supra-majoritarian process" (NUSSBAUM, 2011:42-43).

Regarding the implementation of the capabilities, Nussbaum asserts "the major avenue of implementation of the Central Capabilities is a nation's system of constitutional adjudication involving fundamental rights". Also, the implementation needs to be focused on offering choices, instead of imposing certain behaviors (NUSSBAUM, 1995:97).

Nussbaum recognizes that some capabilities are very important for the development of others, considering its interrelation. She identifies some of them, considering the specific situation of women in India: education, ownership and affiliation (NUSSBAUM, 1995: 98-99).

In opposition, the authors also mention the "corrosive disadvantage", capabilities failures that lead to failure in other fields, mostly related to marginalization and group-based 
powerlessness. Examples are racial discrimination and inability to speak the local language (NUSSBAUM, 1995:99).

To conclude the presentation of the theory, it is relevant to stress the centrality of freedom in the approach. Capability is seen as opportunity to select, freedom to choose. Such freedom has an intrinsic value and should not be evaluated by the best use that can be made of them. The focus on freedom to choose is relevant in order to respect plurality of thoughts and religions, what implicates a conception of a political liberalism. Such freedom does not apply for children, which depends on some sorts of compulsory mechanisms to the development of basic capabilities. Also, regarding freedom to do things that could harm capabilities (such as the use of drugs or the possibility to sell organs), Nussbaum defends that it would be justified the possibility of "reasonable safety regulation", as long as such interference does not infringes the human dignity (NUSSBAUM, 1995:26-27).

\section{GENDER AND CAPABILITIES APPROACH}

A central matter of discussion in the capabilities approach is the gender equality. Nussbaum highlights the importance of the capabilities approach for women affirming that "being a woman is indeed not yet a way of being a human being. Women in much of the world lack support for the most central human functions, and this denial of support is frequently caused by their being women" (NUSSBAUM, 1995:104).

The list of capabilities presented by Nussbaum is one for all humankind, what includes men and women equally. The author offers a counter-position for arguments that would demand elaboration of two different standards of capabilities and human functionings, corresponding to "the different 'natures' of the male and female" (NUSSBAUM, 1995:98).

These arguments are split in two positions: one that suggests male and female should be assigned with the same list of functionings, but exercise them in different spheres of life. According to Nussbaum, Musonius (first century philosopher) understands that even if the list of functionings is the same, it should be exercised by women in the domestic sphere and by men in the public sphere. The author asserts such gender division as a social construct that have often been proven oppressive to women and refuses the central arguments that could sustain 
such position, namely biological differences and contingent social facts (NUSSBAUM, 1995:99-100).

The second position suggests that there should be two separated list of functions. As a response, firstly the author points out the lack of responsible scientific evidence that support such separated set of basic capabilities. Even when this differentiation is proved, they remain in very specific areas, not general and basic capabilities listed by Nussbaum. In addition, as the gender differentiation is embedded socially and historically, it would be next to impossible to get necessary evidence of separated basic capabilities (NUSSBAUM, 1995:102). Nussbaum focuses on women in developing world, considering the intimate relation between gender inequality and poverty (NUSSBAUM, 2001).

An interference in some aspects of the life is defended by Nussbaum in order to achieve full realization of women equality. The author stresses that, sometimes, religious believes are prejudicial to women, or the belief that the private sphere should remain immune to legal regulation. In both occasions, the solution should be priority on the protection of central capabilities, even when imposing a burden to free exercise of religion or interference on private life (NUSSBAUM, 2011:146-149). Freedom of religion should not be understood as limitless license for a small number of religious leaders to perpetuate inequality and misery, as it should be limited in order to sustain equality of valuable capabilities (NUSSBAUM, 2001:167-240).

Regarding sexual orientation, the author defends the legality of same sex wedding, since they promote central capabilities (NUSSBAUM, 2011:149).

\section{CAPABILITIES APPROACH AS A COUNTER THEORY}

For both Sen and Nussbaum, the capability approach can be understood as a central counter-theory in the social justice field, criticizing previews approaches and presenting a new perspective.

The first dominant approach that is criticized is the approach based on gross domestic product (GDP). The GDP approach is influenced by trickle-down theory (economic growth directly leads to improvement of life quality). It is considered an easy and transparent way of measuring a country success. However, several critics are offered: GDP growth does not measure depreciation of capital goods; value of nonmarket household work is not considered; 
the approach does not measure distribution; does not consider complexity of life quality (NUSSBAUM, 2011:46-50).

Nussbaum presents some practical examples to demonstrate the insufficiency of the GDP analysis: the difference of quality of life among Indian states; the difference in gender equality between China and India; and the particularities of the so called "black America" (distinguishable rates of quality life of Afro-Americans in the United States) (NUSSBAUM, 2011:46-50).

The utilitarian approach is also object of criticism. For this theory, quality of life should be assured by utility, and utility is understood as satisfaction of preferences (BENTHAN, 1982). Nussbaum offers the following critics: the approach does not consider inequality among minorities; it aims for simplicity in complex aspects of life; satisfaction is not necessarily related to any activity; and it undermines the importance of freedom. Sen offers an additional critic, namely, the concept of adaptive preferences: people learn sometimes to not to want what they cannot have. In other words, preferences are usually shaped by unjust backgrounds and may not reflect the best available scenario (NUSSBAUM, 2011:50-55). Lastly, according Nussbaum, such a theory stimulates the maintenance of factual situations of deprivation, as it is frequently seen as natural. The traditional system of discrimination is internalized as personal preferences, supporting the status quo (NUSSBAUM, 1995: 92).

Despite the criticism, Nussbaum recognizes improvements of such theory. Utilitarianism has the advantage of taking people's desires seriously and desires are an important element to analyze stability and political justification of the view proposed by Nussbaum (NUSSBAUM, 2011:84).

The last theory criticized by Nussbaum is the resource-based approach, that claims for equal distribution of basic resources (primary goods), as defended by Rawls (1999). Nussbaum offers the following critics: people have differing needs for resources (some differences are physical, some are created by persistent social inequalities); the theory does not consider nonmonetary elements, such as respect, inclusion or religion freedom (NUSSBAUM, 2011: 5658); and the lack of consideration of multiples impediments to functioning, including the ones imposed by traditional norms and values (NUSSBAUM, 1995: 93).

\section{HUMAN RIGHTS AND CAPABILITIES APPROACH}


For Nussbaum, the capabilities approach is one of the human rights approaches'species, with a close correlation of ground and contents. The author states that the capabilities approach sustains the human rights approach by its theoretical explicitness of basic notions and specific formulations (NUSSBAUM, 2001:63).

Nussbaum distinguish two possible interpretations for the use of "right" in relation to capabilities. The first is represented by the statement " $\mathrm{A}$ has a right to X", meaning a claim for fulfillment of capabilities just by the virtue of being human. The second is simplified in the say "country C gives citizens the right to X", what would mean that in the factual background the government indeed secure the basic capability for its citizens, promoting simultaneously both internal and external components of capabilities (NUSSBAUM,1997: 293-294). The capabilities approach highlights the second interpretation, considering that a right has been given only if there are effective measures to give people access to capabilities, and not only a language that exists on paper (NUSSBAUM, 2003:38).

Rights and combined capabilities are equivalent in the sense that the state has a duty to respond to any claim that is done by anyone just by the virtue of being human. In this way, “capabilities are the goals of public planning” (NUSSBAUM, 1997: 293), or, in other words, the capabilities approach imposes moral duties to governments, which are implemented by fundamental rights choices.

The capabilities approach offers an essential contribution when analyzing the effectiveness of fundamental rights, as it considers that rights are only secured to people when they are assured the relevant capabilities to function in that area. This parameter of evaluation can be ultimately extended to analysis of social justice. In the words of Nussbaum, "To the extent that rights are used in defining social justice, we should not grant that the society is just unless the capabilities have been effectively achieved." (NUSSBAUM, 2003:37).

In this way, it brings to the right an argument for the defense of well-fare or positive rights. The central capabilities should be considered a source of principles to guide political institutions, as recognition of capabilities entitlement implies the imposition of ethical duties to the state, which are morally binding. For Nussbaum, "any government that fails to secure basic entitlements has failed in its most essential task. If a capability really belongs on the list, then governments have the obligation to protect and secure it, using law and public policy to achieve this end" (NUSSBAUM, 2011:168). 
The relation of human rights and capabilities is presented by Sen based upon the distinction of two different (but complementary) components of freedom: process and substantive opportunities. As human rights are rights to certain specific freedoms, they are divided into the two aspects. The capability concept helps to elucidate the meaning of the element "opportunity", as "seeing opportunity in terms of capability allows us to distinguish appropriately between (i) whether a person is actually able to do things she would value doing, and (ii) whether she possesses the means or instruments or permissions to pursue what she would like to do" (SEN, 2005: 152-153). On the other hand, the capability approach does not offer an adequate apparat for dealing with the process aspect of freedom, demanding supplementation by considerations of fair processes. In conclusion, for Sen human rights and capabilities are intimate concepts, but they should not subsume entirely within the other, as right to process cannot be analyzed by the capability approach (SEN, 2005: 163).

Human rights theories are usually criticized by feminist approaches by being male centered, not including elements that are central for sex equality. The theory proposed by Nussbaum supplies that demand, as the capabilities approach is particularly concerned with the development of women's capabilities, incorporating some concerns such as the right to physical integrity, protection against sexual harassment and freedom from domestic violence (NUSSBAUM, 2003:37). It also suggests a special focus on positive actions towards gender equality, promoting mechanisms to guarantee basic entitlements for women, considering factual situation of inequality.

Besides that, the theory is focused on the start point of the people, considering their foreground and limitations. For women, that means recognizing inequalities within the family and the society and considering them essential for any attempt to enforce human rights, offering a more adequate approach for gender equality (NUSSBAUM, 2003:39).

Another very important contribution from Nussbaum work to human rights is the concern with vulnerable groups, particularly children, elderly and the mentally and physically handicapped. These groups are usually under injustice in most societies and, as a response, any theory of social justice should offer them an adequate concern. It is noteworthy that care towards these groups is usually a female incumbency, usually unrecognized and not rewarded, increasing gender inequality (NUSSBAUM, 2002). By highlighting special care needed in order to offer children, elderly and the mentally and physically handicapped access to basic capabilities, Nussbaum's approach presents an increment to human rights practice. 
Both human rights practice and capabilities approach are centered in the concept of human dignity and both aim at achieving improvement in the quality of life of every human being. The capabilities approach offers a framework for identification of the content of such rights. Furthermore, it also contributes to reinforcement of human dignity and universality of rights, even though with special attention to vulnerable groups and their peculiarities. Lastly, with the parameters proposed by the capabilities approach it is possible to evaluate the effectiveness of human rights and therefore to compare the development within different countries.

\section{CRITICS TO THE CAPABILITIES APPROACH}

The central criticism of the capabilities approach is related to its universalism and are proposed by relativist theories. There are three critics in this way.

First, the capabilities approach is accused of neglecting historical and cultural difference. Answering that, Nussbaum states that the list of capabilities is vague and general, in order to allow, for each of its components, the possibility of multiple specifications, which should be embedded in a cultural and historical context that shape, at the same time, the conceptions used by citizens and their experiences (NUSSBAUM, 1995: 93).

Second, the critics defend that the capabilities approach neglects personal autonomy, as it removes from the citizen the opportunity to make their own choices about the necessary elements for a good life. Nussbaum answers the criticism with three arguments. First, the list represents only capabilities, leaving space for choices of functions, Secondly, considering the central role that the list provides for practical reasoning, the capability of choice is one of the most central capabilities promoted. Lastly, the author's approach considers that choice only flourishes in relation to material and social conditions, and not pure spontaneously (NUSSBAUM, 1995: 93).

The last relativist critic is related to prejudicial application, or, in other words, the possibility that women (or other vulnerable group of people) would be denied the full condition as human being and so be denied of the basic capabilities. Nussbaum refuses the criticism by affirming that "to deny humanness to beings with whom one lives in conversation and interaction is a fragile sort of self-deceptive stratagem, vulnerable to sustained and consistent 
reflection, and also to experiences that cut through self-deceptive rationalization" (NUSSBAUM, 1995: 96).

Wolf presents a critic to the essentialism of Nussbaum's proposals: the capabilities listed are considered essential to the living of a human life or a good human life. The proposition is considered "extremely strong", and the list of functions should stays open for changes after empirical investigation, deep reflection and dialogue (WOLF, 1995:108). The critic is endorsed by Crocker, that recommends "Nussbaum should replace her sharp 'threshold' of necessary and sufficient conditions with a 'more or less' minimum for what counts as human" (CROCKER, 1995: 173).

An example of the problems that such essentialism could imply is related to the individualistic approach. According to Nussbaum, the capabilities are individual and the government actuation should promote only individual capabilities (NUSSBAUM, 2011: 36). For indigenous communities in Latin America, the collective dimension is central for cultural, social and economic development and can only be promoted collectively. In addition, the individual right to property (capability 10) is for these peoples an inadequate concept as their culture is founded on collective use of the lands (STAVENHAGEN, 1988).

Regarding the universalism of the list of capabilities, Sen presents reluctance to accept a canonical list apart from an appropriate specification of the context of its use. The author recognizes the importance of elaboration of capabilities lists, but objects to "any proposal of a grand mausoleum to one fixed and final list of capabilities" (SEN, 2005: 161). Another central element for disapproval is, for Sen, the "diminution of the domain of public reasoning", as the list is elaborated by theorists without any social discussion, thwarting a future public participation on the object and purpose of such list (SEN, 2005: 158). In the words of the author, "that would be not only a denial of the reach of democracy, but also a misunderstanding of what pure theory can do, completely divorced from the particular social reality that any particular society faces" (SEN, 2005: 158).

Nussbaum refutes those criticism affirming that the list is open-ended, it has undergone modification and might undergo further alteration considering new criticism. That means, even though the list has an essential approach, it might be adaptable to new evaluations, subject to supplementation or deletion (NUSSBAUM, 2003:41-42). Nussbaum actually goes further and criticizes Sen for the lack of a clear enumeration of capabilities, affirming that it is not enough to state that a society must have social justice, but it must be clear what the content of such 
conception is. In her words, in the absence of a list it "would be impossible to say whether the society in question was just or unjust" (NUSSBAUM; 2003:46-47).

There is a specific point of the Nussbaum proposal that could be better developed in the future, allowing a clarification of the purpose. The concept of gender in Nussbaum is a naturalistic one, adopting the biological concept of men and women. She recognizes gender division as a social construct, embedded historically, but does not assume the social construction of the binary concept of gender. In this regard, Nussbaum (1999) wrote an article aggressively criticizing Judith Butller, a post-structuralist philosopher and feminist that challenge traditional binary concept of gender, proposing a queer theory ${ }^{1}$. The controversy is actually a debate between the second and the third wave of feminism.

\section{CONCLUSION}

The capabilities approach presented by Nussbaum offers an interesting approach to human development, proposing central criticism to development approaches that could guide the actuation of governments worldwide. It offers paramount contribution to the human rights practice, specifying the content of life with dignity and proposing detailed orientation for governments in the fulfillment of social justice.

Nussbaum's particular focus on women is an essential proposition in the quest for gender inequality, both through the recognition of a factual background of injustice and violence against women, and through the proposal of goals to be achieved for overcoming of women's marginalization. The theory offers undisputed contributions to the human rights practice, clarifying several points of doubt and enabling evaluation and comparison of human rights standards.

However, as critics of the theory have suggested, the proposed list of universal capabilities, based on an essentialist and individualistic point of view, can exclude specificities of some groups around the world, contradictorily impairing a universal application.

It is essential to consider the list an attempt to suggest general parameters for public reasoning, and not a closed set of components. When applying the list to practical cases involving human rights, the list should be confronted with local and historical situation in order to avoid generalization and incompatibilities, recognizing that it might be incomplete and some important capabilities might be absent from the list. 


\section{NOTES}

${ }^{1}$ For a more detailed analysis of the controversy, see: Christina Wald, "Martha C. Nussbaum versus Judith Butler oder ,Old-style'-Feminismus versus poststrukturalistische GenderTheorie." in Ralf Klausnitzer (ed) Kontroversen in der Literaturtheorie - Literaturtheorie in der Kontroverse (Lang, 2007).

\section{BIBLIOGRAPHICAL REFERENCES}

ARROW, Kenneth J. Social Choice and Individual Values. New York: Wiley, 1963.

BENTHAM, Jeremy. An introduction to the principles of morals and legislation. Lonndon: Methuen, 1982.

CROCKER, David A. Functioning and capability: the foundations of Sen's and Nussbaum's development ethic. In: NUSSBAUM, Martha C. GLOVER, Jonathan (eds). Women, Culture and development: a study of human capabilities. Oxford: OUP, 1995.

HAYEK, F. A. Law, Legislation and Liberty: A New Statement of the Liberal Principles of Justice and Political Economy. Michigan: Routledge, 2013

FRASER, Nancy; HONNETH, Axel. Redistribution or Recognition? A Political-Philosophical Exchange. London: Verso, 2003.

NUSSBAUM, Martha C. GLOVER, Jonathan (eds). Women, Culture and development: a study of human capabilities. Oxford: OUP, 1995.

. Human capabilities, female human bodies. In: NUSSBAUM, Martha C. GLOVER, Jonathan (eds). Women, Culture and development: a study of human capabilities. Oxford: OUP, 1995.

. "Capabilities and Human Rights". Fordham Law Review, New York, v.66. n.273, p. 273-300, 1997. Available at: https://ir.lawnet.fordham.edu/flr/vol66/iss2/2. Access on Jul. 03 2019.

. "The Professor of Parody". The New Republic Online, New York, 1999. (1999) Available at: 〈http://www.tnr.com/index.mhtml $>$. Access on May 042018.

Women and human development: the capabilities approach. New York: Cambridge University Press, 2001, 336 p. 
. Capabilities and Social Justice. International Studies Review, [s.l.], v. 4, n. 2, p. 123 135, Summer 2002.

. "Don't smile so much: philosophy and women on 1970's". In: ALCOFF, Linda M (ed.). Singing in the fire. Lanham: Rowman and Littlefield, 2003, 171 p.

Capabilities as fundamental entitlements: Sen and social justice. Feminist Economics, [s.1.], v. 9, n. 2-3, p.33-59, jan. 2003.

Human Rights and Human Capabilities. Harvard Human Rights Journal, [s.l.], v. 1, n. 20, p.21-24, jan. 2007.

Creating capabilities. Cambridge: Belknap Press, 2011, 256 p.

SEN, Amartya. "The concept of development". In: CHENERY, Hollis; SRINIVASAN, T.N. Handbook of Development Economics. Amsterdam: North Holland, 1988.

"Capability and well-being". In: NUSSBAUM, Marta. SEN, Amartya (eds.). The quality of life. Oxford: OUP, 1993.

."Human Rights and Capabilities". Journal of Human Development, London, v.06, n. 1, p.151-166, july 2005. Availabe at: <https://www.unicef.org/socialpolicy/files/Human_Rights_and_Capabilities.pdf >.

STAVENHAGEN, R. Derecho indigena y derechos humanos en América Latina. Mexico City: El Colegio de México, 1988.

RAWLS, John. A theory of justice. Harvard: Harvard University Press, 1999.

REICHER, Stella Camlot. Capacidades e direitos humanos: uma análise conceitual sob a ótica de Martha Nussbaum. 2009. 111 f. Dissertação (Mestrado) - Curso de Direito, Universidade de Sao Paulo, Sao Paulo, 2009.

SKINNER, David. “Awards and Honors: 2017”. In: LECTURER, Jefferson. Martha C. Nussbaum. Washington: National Endowment for the Humanities, 2017. Availabe at: <https://www.neh.gov/about/awards/jefferson-lecture/martha-nussbaum-biography>. Access on May 042018.

WOLF, Susan. "Martha C. Nussbaum: human capabilities, female human beings: commentary". In: NUSSBAUM, Martha C. GLOVER, Jonathan (eds). Women, Culture and development: a study of human capabilities. Oxford: OUP, 1995.

Trabalho recebido em 04 de junho de 2019

Aceito em 31 de julho de 2020 
Quaestio Iuris

vol. $13, \mathrm{n}^{\circ} .02$, Rio de Janeiro, 2020. pp. 528-546 DOI: $10.12957 /$ rqi.2020.45898 